\title{
Peer Perceptions of Social Skills in Socially Anxious and Nonanxious Adolescents
}

\author{
Anne C. Miers • Anke W. Blöte • P. Michiel Westenberg
}

Published online: 13 August 2009

(C) The Author(s) 2009. This article is published with open access at Springerlink.com

\begin{abstract}
Previous studies using adult observers are inconsistent with regard to social skills deficits in nonclinical socially anxious youth. The present study investigated whether same age peers perceive a lack of social skills in the socially anxious. Twenty high and 20 low socially anxious adolescents (13-17 years old) were recorded giving a 5-min speech. Unfamiliar peer observers $(12-17$ years old) viewed the speech samples and rated four social skills: speech content, facial expressions, posture and body movement, and way of speaking. Peer observers perceived high socially anxious adolescents as significantly poorer than low socially anxious adolescents on all four social skills. Moreover, for all skills except facial expressions, group differences could not be attributed to adolescents' self-reported level of depression. We suggest that therapists take the perceptions of same age peers into account when assessing the social skills of socially anxious youth.
\end{abstract}

Keywords Social anxiety - Adolescence - Peer perceptions . Social skills deficit $\cdot$ Self-evaluations

Recent studies show that socially anxious children and adolescents hold negative expectations and evaluations concerning their performance in social situations (Alfano et al. 2006; Cartwright-Hatton et al. 2005; InderbitzenNolan et al. 2007; Spence et al. 1999). The two main cognitive theories of social phobia (Clark and Wells 1995; Rapee and Heimberg 1997) imply that these negative evaluations develop partly as a consequence of prior social experiences and feedback from others. Therefore, negative

A. C. Miers $(\bowtie) \cdot$ A. W. Blöte $\cdot$ P. M. Westenberg Institute of Psychology, Unit Developmental and Educational Psychology, Leiden University,

P.O. Box 9555, 2300 RB Leiden, The Netherlands

e-mail: acmiers@fsw.leidenuniv.nl self-evaluations may arise as a result of, or at least be maintained by the reactions socially anxious children and adolescents ${ }^{1}$ receive from their peers during social interactions. But why would socially anxious youth experience these negative outcomes from their social interactions? What is it about their behavior that peers do not like? The present study investigated how same age peers perceive the social skills of socially anxious as compared to nonanxious adolescents.

The idea that socially anxious youth receive negative responses from their peers is supported by observational studies that directly examined peer behavior toward socially anxious youth in their social environments (Blöte et al. 2007; Spence et al. 1999). Spence et al. (1999) observed children's (7-14 years old) peer interactions in the classroom and playground. Children diagnosed with social phobia received fewer positive responses from peers compared with children without social phobia. In the Blöte et al. (2007) study an observer rated class behavior during adolescents' (13-16 years old) oral presentations in the classroom. The observations showed that socially anxious speakers were treated more negatively by their classmates than speakers with low self-reported social anxiety.

Furthermore, sociometric studies consistently report that (socially) anxious youth are actively disliked and neglected by their peer group (Greco and Morris 2005). In these studies sociometric status is usually measured by nomination; participants nominate the peers they like the most and like least (Poulin and Dishion 2008). From the frequently used sociometric categories popular, rejected, neglected, average, and controversial the categories most commonly linked to heightened social anxiety are rejected and

\footnotetext{
${ }^{1}$ For brevity the term youth will be used to refer to both children and adolescents unless otherwise specified.
} 
neglected (Greco and Morris 2005). For example, Strauss et al. (1988) investigated the peer social status of a group of 6-13 year old children with anxiety disorders. A significantly higher proportion of these children met criteria for neglected sociometric status compared to the control and conduct-disorder groups. Moreover, only one child with an anxiety disorder was rated as popular by classmates. Similarly, in a longitudinal study conducted from kindergarten to 4th grade, Gazelle and Ladd (2003) reported associations between (socially) anxious solitude, peer rejection and exclusion.

These findings suggest that socially anxious youth have good reason to expect negative treatment and feedback from others. However, in both the peer nomination literature and the studies of Blöte et al. (2007) and Spence et al. (1999) peer reactions are investigated within the context of ongoing social relationships. Therefore, the influence of a child's longstanding social reputation cannot be disentangled from a specific reaction to the child's behavior or social anxiety level (Hymel et al. 1990). To address this issue, Verduin and Kendall (2008) examined how children (9.5-13 years old) with and without anxiety disorders are perceived by unfamiliar peers of the same age. Same age peers rated the degree to which they liked the children and to what extent the children displayed observable symptoms of anxiety during a speech task. Children with social phobia were less liked than other children and this association was independent of whether or not their anxious symptoms were perceived by peers. Verduin and Kendall (2008) questioned why, if socially anxious children do not always appear more anxious, they are disliked. The authors suggested that poorer social performance or lack of social skills on the part of socially anxious children could explain why peers react negatively.

\section{Social Skills Deficits in Socially Anxious Youth}

The possibility of social skills deficits in socially anxious youth has also been proposed by other authors as one of the reasons for negative treatment by peers (Greco and Morris 2005; Spence et al. 1999). However, the literature does not consistently show poorer social skills in socially anxious youth, as rated by adult observers. Whereas a few studies found significant skills differences between socially anxious and nonanxious youth on measures like performance effectiveness or social skillfulness (Alfano et al. 2006; Alfano et al. 2008; Beidel et al. 1999; Beidel et al. 2007), others did not (Cartwright-Hatton et al. 2005; Erath et al. 2007). Finding skills deficits may depend on the sample employed. In general, studies that found skills deficits used clinical samples of social phobic youth while studies that did not find deficits used high socially anxious youth derived from a normal population. Nevertheless, as shown in the studies by Inderbitzen-Nolan et al. (2007) and Morgan and Banerjee (2006) skills deficits are not limited to clinical populations. Thus, it is possible that inconsistent findings are specific to nonclinical samples of socially anxious youth. In these samples, social skills deficits might be less severe than in clinical groups and therefore more difficult to perceive by adults.

In this light it seems particularly important to ask same age peers to rate social skills as they will be more sensitive than adults to small deviations in the behavior of other youth. Judgments from same age peers are also probably more consequential for the child's developing sense of social (in)adequacy. This is particularly true for the adolescent period. Research shows that adolescents' social interactions are increasingly dominated by peers (Hartup 1996; Scholte and Van Aken 2006). Adolescents spend more time in peer groups than adults (Brown 2004) and their perception of support from same-sex friendships rises between late childhood and mid-adolescence (Furman and Buhrmester 1992). Yet, to the best of our knowledge no study has employed same age peers as observers of social skills in socially anxious adolescents.

It is not clear which social skills peers might perceive as lacking and on what behavioral level (i.e., micro, midi, global) the shortcomings might be noticed. Micro skills are highly specific behaviors such as number of smiles or time spent speaking, measured using frequency counts and/or duration (Baker and Edelmann 2002; Monti et al. 1984). In contrast, a global-level approach is general (e.g., "overall social skills") and skill is typically measured using just one rating scale (Boice and Monti 1982). Some of the aforementioned studies employing adult observers measured skills on a micro-level, such as use of eye contact, latency and length of response (e.g., Morgan and Banerjee 2006; Spence et al. 1999) while others used global ratings of performance effectiveness or social skillfulness (e.g., Erath et al. 2007; Inderbitzen-Nolan et al. 2007). A third group of studies measured both micro - and globallevel skills (Alfano et al. 2006, 2008; Beidel et al. 1999; Beidel et al. 2007; Cartwright-Hatton et al. 2005). For both micro- and global-level skills inconsistent findings are evident across studies. For example, Alfano et al. (2008) found that socially phobic adolescents used appropriate eye contact significantly less often than a control group of adolescents. However, the studies of Alfano et al. (2006) and Spence et al. (1999) do not support this finding. Similarly, in some studies measuring global-level skills observers rated socially anxious youth as significantly less skillful than their nonanxious counterparts (Alfano et al. 2006, 2008; Beidel et al. 1999; Beidel et al. 2007; Inderbitzen-Nolan et al. 2007) but not in other studies (Cartwright-Hatton et al. 2005; Erath et al. 2007). 
Instead of measuring social skills at either a micro- or a global- level, studies with socially anxious adults advocate using a midi-level approach (Monti et al. 1984). A midilevel approach combines the specificity of the micro-level and the practicality of the global-level by measuring particular categories of behavior (e.g., facial expression, gestures, voice, and posture) on a rating scale. Based on human ethology research the behavioral categories are broken down into specific descriptions of what constitutes the behavior. For example, Monti et al. (1984) specify posture as "ranging from a rigid, tense and apparently uncomfortable stance of sitting to a relaxed and apparently comfortable style" (p. 655). A midi-level approach has been shown to successfully discriminate between socially anxious and nonanxious adults whereas studies employing micro-level measurements fail to consistently distinguish between social anxiety groups (Baker and Edelmann 2002). For this reason and because a midi-level approach has not yet been employed with adolescents, the current study measures midi-level social skills.

Social skills deficits are not only associated with social anxiety but also with depression in both clinical and nonclinical samples (Segrin 2000; Van Beek et al. 2006). Moreover depression, like social anxiety, is linked to difficulties in peer relationships and peer rejection (see Zimmer-Gembeck et al. 2007 for a review). Because anxiety disorders in general, including social anxiety, are strongly comorbid with depression (Starr and Davila 2008), we considered it important to investigate the specificity of peer perceived skills deficits to social anxiety. In this way, we could explore whether it is social anxiety and not depression that elicits negative responses from peers.

\section{The Present Study}

In short, it is possible that poor social skills as perceived by peers are the reason that socially anxious youth are negatively treated by these peers. In turn, negative treatment makes socially anxious youth feel that their social performance is poor, resulting in low self-evaluations. As the first step in this model-whether peers perceive the social skills of socially anxious youth as poor-has never been investigated, the present study was designed to do just this.

A group of nonreferred adolescents with high selfreported levels of social anxiety and a group with lower levels (the control group) took part in the Leiden Public Speaking Task (Leiden-PST; Westenberg et al. in press). Public speaking performances were recorded and shown to peer observers at a later date. We chose to study adolescents because this period is coupled, on the one hand, with an increasing importance of peer relationships (as discussed earlier), and on the other hand, with an increase in fear of negative evaluation (Weems and Costa 2005; Westenberg et al. 2007) and an early to mid-teen onset of social phobia (Rapee and Spence 2004). In accordance with Verduin and Kendall (2008) and to avoid the influence of social reputation on peer perceptions (Hymel et al. 1990), we specifically chose unfamiliar peer observers, similar in age. We included a minimum of 20 peer observers per adolescent so that we could measure an average reaction from a group, closely mirroring a school classroom situation. This type of situation was considered to be more relevant to the daily lives of anxious and nonanxious youth than the more standard situation in which objective ratings from a few adult observers are collected. Peer observers rated four midi-level social skills important for this performance situation: speech content, facial expressions, posture and body movement, and way of speaking (Monti et al. 1984; Segrin 2000).

We investigated the following research questions: (1) Do unfamiliar peers perceive differences in individual skills (speech content, facial expressions, posture/body movement, and way of speaking) between high socially anxious adolescents and a control group? and (2) If social skills deficits are perceived by unfamiliar peers, are these solely attributable to adolescents' social anxiety level or can they (partly) be accounted for by depression? In addition, we explored whether some skills are more important than others in distinguishing high socially anxious adolescents from the control group.

\section{Method}

\section{Participants}

Participants were 40 low and high socially anxious adolescents selected from a larger community sample of 201 Dutch secondary school students. Students took part in the Social Anxiety and Normal Development study (SAND study, Leiden). The SAND study was approved by the University's Medical Ethical Committee. Prior to participation in the SAND study informed parental and adolescent consent was obtained in writing. From the larger sample we selected 20 high socially anxious, 10 female and 10 male, using the cut-off score of $>1 S D$ above the mean on the Social Anxiety Scale for Adolescents (SAS-A; La Greca and Lopez 1998). To account for a social anxiety gender difference in the community sample, girls and boys were independently selected according to their gender specific cut-off score. To match the high socially anxious group ten girls and ten boys with a SAS-A score $<0.5 S D$ below the mean were selected for the control group. The 40 adolescents were aged between 13 and 17 years $(M=$ 14.50, $S D=0.99)$. Mean SAS-A scores for adolescents in 
the high social anxiety and control groups were $55.71(S D=$ $6.74)$ and $21.60(S D=3.78)$ respectively, $t(29.84)=19.73$, $p<.01$. These group means meet the criteria for high and low social anxiety groups as recommended by La Greca (1998). Social anxiety groups were comparable on age, frequency of studying at pre-university education level, living with both biological parents, and having a Dutch or other ethnic background. For clarity, these 40 adolescents are referred to as 'speakers' in this section.

\section{Peer Observers}

Each speaker was rated by a minimum of 20 peer observers (maximum number was 26). In total 226 pupils acted as peer observers. They were recruited from a secondary school located in a city at some distance from the school attended by speakers. This was to ensure that observers did not know the speakers. Peer observers attended the same education levels as speakers and were of a comparable age, between 12 and 17 years $(M=14.46$ years, $S D=0.89)$. Peer observers included 110 boys and 116 girls.

\section{Materials}

\section{Speaker Measures}

Social Anxiety Scale for Adolescents (SAS-A; La Greca and Lopez 1998) Social anxiety was measured with the Dutch translation of the SAS-A (Koot \& Utens, unpublished). The SAS-A contains 18 descriptors (e.g., "I worry about what other kids think of me" and "I get nervous when I meet new kids") and 4 filler items. Respondents are asked to rate each item according to the degree to which the item "is true for you" ( $1=$ not at all, $5=$ all the time). The sum score over all 18 items was used in the present study. This widely used instrument has good psychometric properties in Dutch community samples (Blöte et al. 2007; Miers et al. 2008).

\section{Children's Depression Inventory (CDI; Kovacs 1985) The} Dutch translation of the Children's Depression Inventory (Timbremont and Braet 2002) measured speakers' selfreported depression. The CDI includes 27 items that assess behavioral, affective and cognitive signs of depression. For each item respondents are presented with three statements and asked to choose the one which best describes how they have felt in the past 2 weeks. For example, "I do most things O.K.," "I do many things wrong" and "I do everything wrong." Statements are scored from 0 (least depressive) to 2 (most depressive). A total score is calculated by summing scores across all items. This instrument has good psychometric properties in nonclinical samples (e.g., Craighead et al. 1998) and the Dutch version also shows good reliability and validity (Timbremont and Braet 2002). For ethical reasons, one item asking about suicide was removed from the questionnaire. This is a common approach in nonclinical samples (e.g., Gregory et al. 2007).

\section{Peer Observer Measures}

Skills Rating Scale for Peers (SRSP) The Skills Rating Scale for Peers (SRSP) consists of four items, namely, speech content, facial expressions, posture/body movement, and way of speaking. The SRSP is based on previous studies that measured midi-level nonverbal behaviors associated with social anxiety (e.g., Monti et al. 1984). Peer observers received instructions and examples of each item to guide their ratings of the skills. Speech content was rated on a 5-point likert scale in terms of its clarity, as indicated by the anchor descriptors, 1=unclear, $3=$ neutral, $5=$ clear . For facial expressions observers were asked to think about whether the speaker's facial expressions appear friendly, relaxed or tense. For posture/body movement observers were asked to pay attention to fidgeting, shifting weight from one foot to the other, use of hand gestures and a (un)comfortable stance. Way of speaking included the speaker's tone, speed, volume, use of fluid sentences and how often the speaker uses utterances indicating hesitation or inarticulateness ('um'). These three items were also rated on a 5-point likert scale with anchors: $1=$ poor, $3=$ neutral, $5=$ good.

Prior to calculation of the four social skill scores we checked for possible effects of observer gender on ratings of each social skill for each type of speaker (i.e., socially anxious male and female, nonanxious male and female). ANOVAs revealed no significant effects for observer gender. Therefore, scores for the four skills were calculated by averaging ratings from male and female observers within each set of $20+$ peer observers.

\section{Procedure}

There were two phases to the study's procedure. First, all public speaking performances were recorded onto digital video (DV) tapes (the recording phase). Second, peer observers rated the performances using the SRSP (the peer rating phase).

\section{Recording Phase}

For the Leiden-PST (Westenberg et al. in press) speakers were required to talk for $5 \mathrm{~min}$ about the sort of films they like/dislike and why. Speakers were informed that they will speak in front of a pre-recorded audience and that their speech will be recorded and evaluated at a later date by same age peers and a teacher on aspects such as its clarity and structure. Speakers were explicitly told to prepare for 
their talk and were given a week to do so. This approach was chosen to make the situation comparable to the requirements of a public speaking task at school. Moreover, possible social skills deficits could be captured without being influenced by anxiousness arising as a result of engaging in an unexpected, impromptu speech task. The pre-recorded audience consisted of a group of peers and a teacher behaving in a natural and neutral manner that is, not showing positive or negative behaviors. The lack of audience interaction precludes the possibility that socially anxious speakers' ability to perform skillfully is affected by negative feedback. In addition, the audience is age-matched to the speaker. Speakers' speech performances were recorded using DV tapes and a hard disc recorder and then copied onto digital video discs (DVDs). Speakers had given permission for the speech recordings to be used for research purposes.

\section{Peer Rating Phase}

The 40 speech recordings were compiled onto 10 DVDs, each with four speech samples. Only the first $2 \mathrm{~min}$ of the speech was used. Such short clips, or 'thin slices' of behavior, are argued to provide enough information for accurate judgments of personality variables (Carney et al. 2007). Each set of four speech samples included a boy and girl from the high anxious group and a boy and girl from the control group. Apart from meeting these criteria, selection of the four samples in each set was random. Four different orders of gender and anxiety group were employed in order to reduce order effects on peers' ratings.

Peer observers rated the speech samples at their own school during a regular lesson. They gave assent and their caregivers gave passive consent prior to the rating phase. In total, 20 classes from one secondary school were involved. Peer observers were age-matched to speakers on the basis of grade level. Two Master's level Psychology students led the peer rating sessions during which the teacher remained in the classroom. Within each class a random half of the pupils was given the SRSP and the other half received a different measure not used in the present study. To ensure that the minimum of 20 peer observers per speaker was reached, two classes viewed the same set of four speech samples.

The peer rating session began with an explanation of the study and its procedure. Peer observers were blind to the study's hypotheses and to which social anxiety group the speakers belonged. They were told to complete the SRSP after viewing the 2 min sample of each speaker. Recordings were shown to observers on a projector screen (life size) using a video projector. Observers were first given the opportunity to practice rating the speakers' skills by using a completely different speech sample lasting 2 min. Following the practice session, the four speech samples were presented one by one with enough time after each sample for the SRSP to be completed. The peer rating phase took approximately $25 \mathrm{~min}$.

\section{Data Analyses}

First, we computed bivariate correlations among the four skills (speech content, facial expressions, posture/body movement, and way of speaking). Second, four ANOVAs were conducted to test the effect of social anxiety on the four skills. Third, to check whether skills differences between social anxiety groups were influenced by depression, four ANCOVAs were performed with depression as the covariate. The ANOVAs and ANCOVAs were Bonferroni corrected. Lastly, in order to explore the contribution of each skill rating to social anxiety classification, all four ratings were entered as predictors into logistic regression analyses with social anxiety group membership as the dependent variable. We chose to use three different logistic regression methods: enter, forward and backward stepwise likelihood ratio (Field 2000). Because of the lack of evidence on which to base specific hypotheses about the relative importance of each skill, it would have been premature to exclude one or more skills before conducting the analyses. Therefore, we first used the enter method in order to evaluate the contribution of each skill compared to that of the others. Second, we conducted forward and backward stepwise logistic regressions to explore which skills are the strongest predictors (Field 2000).

\section{Results}

\section{Relationships Among Midi-Level Social Skills}

Correlation analyses among the four skills revealed significant positive intercorrelations (all $r$ 's between .87 and .93 and $p$ 's $<.001$ ). Although Monti et al. (1984) also found high intercorrelations in student and patient samples, with $r$ 's between .55 and .81 , the present correlations are in a higher range. This may be explained by the present study's larger number of observers (at least 20) compared with Monti et al.'s (1984) study. Using a greater number of observers increases the reliability of the mean skill ratings over observers and therefore enhances the strength of correlations among the skills. At the same time, the strong intercorrelations suggest that there is considerable overlap among the four skills.

Skills Differences Between High and Low Socially Anxious Adolescents

Gender of the speaker was initially included as an independent variable. However, all main and interaction 
effects of gender were nonsignificant (all $p$ 's $>.23$ and partial $\eta^{2}$ s $<.04$ ). The analyses were therefore repeated without gender, and these results are reported.

Table 1 shows the results for the first research question: "Do unfamiliar peers perceive differences in speech content, facial expressions, posture and body movement, and way of speaking between high socially anxious adolescents and a control group?" High socially anxious and control groups differed significantly on the ratings of all four skills. Age peers rated the content of high socially anxious adolescents' speech as significantly less clear and their facial expressions, posture and body movement, and way of speaking as poorer compared with the control group. According to effect size guidelines, the effect sizes shown in Table 1 may be considered large (Tabachnick and Fidell 2007).

Before conducting the four ANCOVAs a point-biserial correlation between social anxiety group and adolescents' self-reported depression was calculated. In line with previous research (e.g., La Greca and Harrison 2005) this showed a significant positive relationship, $r_{p b}=.58, p<.001$. The four ANCOVAs controlling for depression revealed similar results to the preceding ANOVAs but with a slightly reduced social anxiety effect. High socially anxious and control groups differed significantly (at $p<.01$, Bonferroni correction) on peer ratings of speech content, $F(1,37)=$ 13.96, partial $\eta^{2}=.27$, posture and body movement, $F(1$, $37)=11.58$, partial $\eta^{2}=.24$, and way of speaking, $F(1,37)=$ 11.00, partial $\eta^{2}=.23$. The difference between social anxiety groups on peer ratings of facial expressions missed significance at the Bonferroni-corrected level, $F(1,37)=$ $6.20, p=.02$, partial $\eta^{2}=.14$.

\section{Logistic Regression of Skills Ratings Predicting Social Anxiety Group Membership}

The first logistic regression showed that the four ratings combined make a significant contribution to the prediction of social anxiety group membership, $\chi^{2}(4)=17.69, p<.01$. This model had an overall classification rate of $80 \%$ and each social skill individually classified at least $70 \%$ of participants correctly. However, as can be seen from Table 2, not one skill was significantly associated with social anxiety. This shows that, as was already suggested by the high intercorrelations among the four skills, the unique contribution of one single skill is small.
Second, the forward and backward logistic regression analyses showed that a prediction based on one rating alone, namely posture and body movement, was sufficient to predict social anxiety, likelihood ratio $\chi^{2}(1)=16.07$, $p<.001$. The $\beta$ coefficient associated with posture and body movement was significantly different from zero, $\beta=-2.31$, Wald $(1)=10.38, p<.01$, and had an odds ratio $(\operatorname{Exp} \beta)$ of 0.10 (95\% Confidence Interval Exp $\beta=0.02-0.41$ ). Posture and body movement classified $75 \%$ of participants correctly and inclusion of the other skills did not significantly improve this prediction.

\section{Discussion}

The present study addressed two main questions: do unfamiliar peers perceive differences in individual social skills between high socially anxious adolescents and a control group and, if so, can these differences be (partly) accounted for by depression? In answer to the first question the current study shows that unfamiliar same age peers do perceive high socially anxious adolescents as less socially skilled than their low anxious counterparts during a speech performance. This group difference held for all four skills: speech content, facial expressions, posture and body movement, and way of speaking. In response to the second question, the anxiety group difference could not be ascribed to depression in the high socially anxious group. After controlling for depression, high socially anxious adolescents' speech content was still perceived as less comprehensible and their posture/movement and way of speaking as less appropriate for the speech. However, depression did play a relatively more important role in facial expression ratings. Finally, we explored whether some skills would be more important in distinguishing high anxious adolescents from the control group. Our findings showed that the four skill ratings are strongly related; none of the skills made a unique contribution to social anxiety group classification.

The poorer ratings received by socially anxious adolescents are consistent with previous studies on peer behavior toward and peer liking ratings of socially anxious and nonanxious youth (Blöte et al. 2007; Spence et al. 1999; Verduin and Kendall 2008). Furthermore, and in addition to these previous studies, the present study directly shows that same age peers readily (within $2 \mathrm{~min}$ ) perceive social skills
Table 1 Means (SDs) of Individual Skill Ratings by Social Anxiety Group

$* p<.01$, Bonferroni correction.

\begin{tabular}{lccccc}
\hline Peer ratings & High anxious & Control group & $d f$ & $F$ & Partial $\eta^{2}$ \\
\hline Speech content & $2.30(0.75)$ & $3.29(0.65)$ & 1,38 & $19.72^{*}$ & 0.34 \\
Facial expressions & $2.24(0.64)$ & $3.05(0.67)$ & 1,38 & $14.84^{*}$ & 0.28 \\
Posture/movement & $1.99(0.54)$ & $2.82(0.62)$ & 1,38 & $20.13^{*}$ & 0.35 \\
Way of speaking & $2.10(0.71)$ & $3.02(0.70)$ & 1,38 & $16.72^{*}$ & 0.31 \\
\hline
\end{tabular}


Table 2 Logistic Regression Results Using Enter Method with Social Anxiety Group as Dependent Variable

\begin{tabular}{lrllllll}
\hline Peer ratings & \multicolumn{1}{l}{$S$} & $S E$ & Wald & $d f$ & $\operatorname{Exp}(\beta)$ & $p$ & $95 \%$ CI Exp $(\beta)$ \\
\hline Speech content & -1.28 & 1.32 & 0.95 & 1 & 0.28 & 0.330 & $0.02-3.66$ \\
Facial expressions & 1.07 & 1.64 & 0.43 & 1 & 2.92 & 0.515 & $0.12-73.31$ \\
Posture/movement & -1.96 & 1.55 & 1.61 & 1 & 0.14 & 0.205 & $0.01-2.91$ \\
Way of speaking & -0.12 & 1.50 & 0.01 & 1 & 0.89 & 0.937 & $0.05-16.79$ \\
\hline
\end{tabular}

differences between high and low socially anxious adolescents. This may explain why socially anxious youth receive negative reactions and feedback from peers in established relationships (Blöte et al. 2007; Spence et al. 1999) and why they are less liked by novel peers (Verduin and Kendall 2008).

In their discussion Verduin and Kendall (2008) recommended that future research investigate which behaviors make anxious children less liked. In this vein, we investigated whether one or more of the four skills would best discriminate the high from low socially anxious group. Due to the strong associations among all four skills we may conclude that it is an overall lack of social skill that is perceived as unattractive by peers. It seems that the four social skills combined represent one underlying factor that creates a global impression of skillfulness. In addition, our findings tentatively suggest that of the four skills, posture and body movement appears to best represent the underlying factor that distinguishes high from low socially anxious adolescents. However, this finding certainly requires replication before more definite conclusions can be drawn.

Socially anxious adolescents were given poorer ratings even after controlling for depression. Thus, despite the skills deficits reported among depressed individuals (Segrin 2000; Van Beek et al. 2006) and the present study's strong relation between social anxiety and depression (c.f., Inderbitzen-Nolan and Walters 2000), depression only partially accounted for the relationship between social anxiety and peer ratings of speech content, posture and body movement, and way of speaking. However, peer ratings of facial expressions seemed to be more influenced by depression. Whether the inappropriate use of facial expressions is more strongly associated with depression than social anxiety is a question that should be addressed in future research.

The current study presents evidence that, in the perception of their peers, a skills deficit does exist in nonclinical socially anxious adolescents. With regard to previous studies using adult observers and nonclinical samples, the present study corroborates the findings of Inderbitzen-Nolan et al. (2007) and Morgan and Banerjee (2006). However, our results contrast with the studies of Cartwright-Hatton et al. (2005) and Erath et al. (2007). It is possible that studies with nonclinical samples would yield consistent results if peer observers were employed instead of adults. Although the evidence from peer observers comes from this study only, the perceived differences between high and low socially anxious adolescents are large and are based on ratings from unfamiliar peers.

If indeed the social skills of socially anxious youth are perceived as poor by same age peers, do these findings help to explain why socially anxious youth hold negative selfevaluations of their social performance? Some previous studies suggest that self-evaluations are biased and not based on the actual social performance, as judged by adult observers (Cartwright-Hatton et al. 2005; Inderbitzen-Nolan et al. 2007). However, in light of the strong peer perceived skills differences found in the current study, one might suspect that the self-evaluations of nonclinically anxious adolescents mirror the perceptions of the critical age group and are therefore unbiased. Whether this is also the case for youth diagnosed with social phobia is unclear. One possibility is that their self-evaluations are indeed biased; their evaluations may be more pervasive and generalize more readily to different types of social situations than the evaluations of youth without a clinical diagnosis. Another possibility is that clinically anxious youth do not have biased self-evaluations either. If they have stronger skills deficits than nonclinical groups, this could result in even higher rejection by peers and consequently lower selfevaluations. Future studies should endeavor to clarify this issue by comparing self - with peer-evaluations in clinical and nonclinical groups of socially anxious youth.

The findings of the current study raise a second question, namely what is the origin of the social skills deficit in socially anxious youth? In order to answer this question, it is important to conduct a longitudinal study in which children are followed from an age that temporally precedes the onset of social anxiety disorder. Such an approach could examine the relative influence of peer group feedback and other factors, such as negative social events, familial processes, and behavioral avoidance on the development of a social skills deficit in socially anxious youth.

This study is not without limitations. First, we did not measure all midi-level skills mentioned in the adult literature, for example self-manipulations, gestures, and sense of timing (Monti et al. 1984). Therefore, it is unclear whether socially anxious adolescents lack all midi-level social skills or just those measured in the present study. Second, the strong intercorrelations observed among the 
four skills could be explained by an observer rating carryover effect from one skill to another. The notion of an overall impression is in line with Alden and Taylor's (2004) conclusion that a 'global negative halo' exists in others' judgments of shy versus non-shy individuals. Future research into the importance of particular skills should employ different observers to rate just one skill each, rather than the same four skills. This would provide stronger support for the conclusion that the general effect across all skills reflects one latent factor, characteristic of the speaker. Third, we cannot rule out the possibility that peer observers perceive a performance deficit rather than a skills deficit (Hopko et al. 2001). The social skills of socially anxious adolescents may be in tact, yet as a result of their anxiety they engage in interfering (safety) behaviors (Clark and Wells 1995), such as talking quickly to avoid awkward pauses or maintaining a very static posture to prevent the body shaking. Such behaviors are likely to be detrimental to social performance, hence the poorer skills ratings received by high anxious adolescents. It would be fruitful for future studies to more carefully distinguish between interfering behaviors that may result in a performance deficit and a real lack of social skills, especially in view of the consequences for treatment.

Finally, it is possible that the poorer skill ratings received by anxious adolescents may be accounted for by perceptions of lesser attractiveness compared to low socially anxious adolescents. It is well established that attractive persons receive more positive attributions from others (Langlois et al. 2000) and attractiveness has been linked to both social skills and social anxiety (Feingold 1992). However, in another study observer rated attractiveness did not correlate with shyness (Jones et al. 1986). It is recommended that future studies address the role of attractiveness in peer ratings of socially anxious individuals.

To conclude, more studies are required to specify exactly which skills are deficient among socially anxious youth and on which behavioral level the most consistent group differences are found. The findings of such studies would contribute to the current debate regarding the inclusion of social skills training in the treatment of social phobia (e.g., Cartwright-Hatton et al. 2005; Inderbitzen-Nolan et al. 2007). In the meantime, our findings suggest that a social skills component is indeed valuable and that therapists include speech content, facial expressions, posture, and way of speaking in their training modules. In line with other researchers advocating the importance of a peer view (Van Beek et al. 2006; Verduin and Kendall 2008) we also recommend that therapists take the reactions and perceptions of peers into account when assessing social skills, in addition to the more standard adult view from either parents or teachers.

Acknowledgements The authors would like to thank Judith Janssen and Silke Tönnies for their valuable contributions to this study.
Open Access This article is distributed under the terms of the Creative Commons Attribution Noncommercial License which permits any noncommercial use, distribution, and reproduction in any medium, provided the original author(s) and source are credited.

\section{References}

Alden, L. E., \& Taylor, C. T. (2004). Interpersonal processes in social phobia. Clinical Psychology Review, 24, 857-882.

Alfano, C. A., Beidel, D. C., \& Turner, S. M. (2006). Cognitive correlates of social phobia among children and adolescents. Journal of Abnormal Child Psychology, 34, 189-201.

Alfano, C. A., Beidel, D. C., \& Turner, S. M. (2008). Negative selfimagery among adolescents with social phobia: A test of an adult model of the disorder. Journal of Clinical Child and Adolescent Psychology, 37, 327-336.

Baker, S. R., \& Edelmann, R. J. (2002). Is social phobia related to lack of social skills? Duration of skill-related behaviours and ratings of behavioural adequacy. British Journal of Clinical Psychology, 41, 243-257.

Beidel, D. C., Turner, S. M., \& Morris, T. L. (1999). Psychopathology of childhood social phobia. Journal of the American Academy of Child and Adolescent Psychiatry, 38, 643-650.

Beidel, D. C., Turner, S. M., Young, B. J., Ammerman, R. T., Sallee, F. R., \& Crosby, L. (2007). Psychopathology of adolescent social phobia. Journal of Psychopathology and Behavioral Assessment, 29, 47-54.

Blöte, A. W., Kint, M. J. W., \& Westenberg, P. M. (2007). Peer behavior toward socially anxious adolescents: Classroom observations. Behaviour Research and Therapy, 45, 2773-2779.

Boice, R., \& Monti, P. M. (1982). Specification of nonverbal behaviors for clinical assessment. Journal of Nonverbal Behavior, 7, 79-94.

Brown, B. (2004). Adolescents' relationships with peers. In R. Lerner \& L. Steinberg (Eds.), Handbook of adolescent psychology (2nd ed., pp. 363-394). New York: Wiley.

Carney, D. R., Colvin, C. R., \& Hall, J. A. (2007). A thin slice perspective on the accuracy of first impressions. Journal of Research in Personality, 41, 1054-1072.

Cartwright-Hatton, S., Tschernitz, N., \& Gomersall, H. (2005). Social anxiety in children: Social skills deficit, or cognitive distortion? Behaviour Research and Therapy, 43, 131-141.

Clark, D. M., \& Wells, A. (1995). A cognitive model of social phobia. In R. G. Heimberg, M. R. Liebowitz, D. A. Hope \& F. R. Schneier (Eds.), Social phobia: Diagnosis, assessment, and treatment (pp. 69-93). New York: The Guilford.

Craighead, W. E., Smucker, M. R., Craighead, L. W., \& Ilardi, S. S. (1998). Factor analysis of the Children's Depression Inventory in a community sample. Psychological Assessment, 10, 156-165.

Erath, S. A., Flanagan, K. S., \& Bierman, K. L. (2007). Social anxiety and peer relations in early adolescence: Behavioral and cognitive factors. Journal of Abnormal Child Psychology, 35, 405-416.

Feingold, A. (1992). Good-looking people are not what we think. Psychological Bulletin, 111, 304-341.

Field, A. P. (2000). Discovering statistics using SPSS for Windows: Advanced techniques for the beginner. London: Sage.

Furman, W., \& Buhrmester, D. (1992). Age and sex differences in perceptions of networks of personal relationships. Child Development, 63, 103-115.

Gazelle, H., \& Ladd, G. W. (2003). Anxious solitude and peer exclusion: A diathesis-stress model of internalizing trajectories in childhood. Child Development, 74, 257-278.

Greco, L. A., \& Morris, T. L. (2005). Factors influencing the link between social anxiety and peer acceptance: Contributions of 
social skills and close friendships during middle childhood. Behavior Therapy, 36, 197-205.

Gregory, A. M., Rijsdijk, F. V., Lau, J. Y. F., Napolitano, M., McGuffin, P., \& Eley, T. C. (2007). Genetic and environmental influences on interpersonal cognitions and associations with depressive symptoms in 8-year-old twins. Journal of Abnormal Psychology, 116, 762-775.

Hartup, W. W. (1996). The company they keep: Friendships and their developmental significance. Child Development, 67, 1-13.

Hopko, D. R., McNeil, D. W., Zvolensky, M. J., \& Eifert, G. H. (2001). The relation between anxiety and skill in performancebased anxiety disorders: A behavioral formulation of social phobia. Behavior Therapy, 32, 185-207.

Hymel, S., Wagner, E., \& Butler, L. J. (1990). Reputational bias: View from the peer group. In S. R. Asher \& J. Coie (Eds.), Peer rejection in childhood (pp. 156-186). Cambridge: Cambridge University Press.

Inderbitzen-Nolan, H. M., \& Walters, K. S. (2000). Social anxiety scale for adolescents: Normative data and further evidence of construct validity. Journal of Clinical Child and Adolescent Psychology, 29, 360-371.

Inderbitzen-Nolan, H. M., Anderson, E. R., \& Johnson, H. S. (2007). Subjective versus objective behavioral ratings following two analogue tasks: A comparison of socially phobic and nonanxious adolescents. Journal of Anxiety Disorders, 21, 76-90.

Jones, W. H., Briggs, S. R., \& Smith, T. G. (1986). Shyness: Conceptualization and measurement. Journal of Personality and Social Psychology, 51, 629-639.

Kovacs, M. (1985). The Children's Depression Inventory (CDI). Psychopharmacology Bulletin, 21, 995-998.

La Greca, A. M. (1998). Manual for the social anxiety scales for children and adolescents. Miami: University of Miami.

La Greca, A. M., \& Harrison, H. M. (2005). Adolescent peer relations, friendships, and romantic relationships: Do they predict social anxiety and depression? Journal of Clinical Child and Adolescent Psychology, 34, 49-61.

La Greca, A. M., \& Lopez, N. (1998). Social anxiety among adolescents: Linkages with peer relations and friendships. Journal of Abnormal Child Psychology, 26, 83-94.

Langlois, J. H., Kalakanis, L., Rubenstein, A. J., Larson, A., Hallam, M., \& Smoot, M. (2000). Maxims or myths of beauty? A metaanalytic and theoretical review. Psychological Bulletin, 126, 390423.

Miers, A. C., Blöte, A. W., Bögels, S. M., \& Westenberg, P. M. (2008). Interpretation bias and social anxiety in adolescents. Journal of Anxiety Disorders, 22, 1462-1471.

Monti, P. M., Boice, R., Fingeret, A. L., Zwick, W. R., Kolko, D., Munroe, S., et al. (1984). Midi-level measurement of social anxiety in psychiatric and non-psychiatric samples. Behaviour Research and Therapy, 22, 651-660.

Morgan, J., \& Banerjee, R. (2006). Social anxiety and self-evaluation of social performance in a nonclinical sample of children. Journal of Clinical Child and Adolescent Psychology, 35, 292-301.
Poulin, F., \& Dishion, T. J. (2008). Methodological issues in the use of peer sociometric nominations with middle school youth. Social Development, 17, 908-921.

Rapee, R. M., \& Heimberg, R. G. (1997). A cognitive-behavioral model of anxiety in social phobia. Behaviour Research and Therapy, 35, 741-756.

Rapee, R. M., \& Spence, S. H. (2004). The etiology of social phobia: Empirical evidence and an initial model. Clinical Psychology Review, 24, 737-767.

Scholte, R. H. J., \& Van Aken, M. A. G. (2006). Peer relations in adolescence. In S. Jackson \& L. Goossens (Eds.), Handbook of adolescent development (pp. 175-199). Hove: Psychology.

Segrin, C. (2000). Social skills deficits associated with depression. Clinical Psychology Review, 20, 379-403.

Spence, S. H., Donovan, C., \& Brechman-Toussaint, M. (1999). Social skills, social outcomes, and cognitive features of childhood social phobia. Journal of Abnormal Psychology, 108, 211-221.

Starr, L. R., \& Davila, J. (2008). Differentiating interpersonal correlates of depressive symptoms and social anxiety in adolescence: Implications for models of comorbidity. Journal of Clinical Child and Adolescent Psychology, 37, 337-349.

Strauss, C. C., Lahey, B. B., Frick, P., Frame, C. L., \& Hynd, G. W. (1988). Peer social status of children with anxiety disorders. Journal of Consulting and Clinical Psychology, 56, 137-141.

Tabachnick, B. G., \& Fidell, L. S. (2007). Using multivariate statistics (5th ed.). New York: Allyn and Bacon.

Timbremont, B., \& Braet, C. (2002). Children's Depression Inventory: Nederlandstalige versie [Children's Depression Inventory: Dutch version]. Lisse: Swets \& Zeitlinger.

Van Beek, Y., Van Dolderen, M. S. M., \& Demon Dubas, J. J. S. (2006). Gender-specific development of nonverbal behaviours and mild depression in adolescence. Journal of Child Psychology and Psychiatry, 47, 1272-1283.

Verduin, T. L., \& Kendall, P. C. (2008). Peer perceptions and liking of children with anxiety disorders. Journal of Abnormal Child Psychology, 36, 459-469.

Weems, C. F., \& Costa, N. M. (2005). Developmental differences in the expression of childhood anxiety symptoms and fears. Journal of the American Academy of Child and Adolescent Psychiatry, 44, 656-663.

Westenberg, P. M., Bokhorst, C. L., Miers, A. C., Sumter, S. R., Kallen, V. L., van Pelt, J., et al. (in press). A prepared speech in front of a pre-recorded audience: Subjective, physiological, and neuroendocrine responses to the Leiden Public Speaking Task. Biological Psychology. doi:10.1016/j.biopsycho. 2009.06.005

Westenberg, P. M., Gullone, E., Bokhorst, C. L., Heyne, D. A., \& King, N. J. (2007). Social evaluation fear in childhood and adolescence: Normative developmental course and continuity of individual differences. British Journal of Developmental Psychology, 25, 471-483.

Zimmer-Gembeck, M. J., Hunter, T. A., \& Pronk, R. (2007). A model of behaviors, peer relations and depression: Perceived social acceptance as a mediator and the divergence of perceptions. Journal of Social and Clinical Psychology, 26, 273-302. 